\title{
ANALISIS SISTEM PENJUALAN DENGAN POINT OF SALES (POS) BERBASIS WEB DI GUDANG KOPI ONCAK
}

\author{
${ }^{1)}$ Bilqis Nabilla Santgani ${ }^{2}$ Filda Angellia \\ Email: ${ }^{1)}$ nbilqis809@gmail.com ${ }^{2)}$ fildaibik57@gmail.com \\ ${ }^{1)}$ 2)Program Studi Sistem Informasi, Fakultas Ilmu Komputer \\ ${ }^{1)}$ 2) Institut Bisnis dan Informatika (IBI) Kosgoro 1957
}

\begin{abstract}
ABSTRAK
Sistem informasi Penjualan dengan Point of Sales (POS) merupakan sistem yang dibangun untuk pencatatan transaksi penjualan dan melakukan proses data pada CV Putri Cahaya Cemerlang (Gudang Kopi Oncak) untuk mempercepat pelayanan dari registrasi sampai dengan pembayaran. Sistem informasi Penjualan POS ini dibangun menggunakan metode Waterfall. Teknik pengumpulan data yang digunakan adalah wawancara, observasi, dan studi literatur untuk menganalisis kebutuhan dan perancangan sistem informasi penjualan dengan POS.

Perancangan sistem informasi penjualan dengan POS ini menggunakan metode Unified Modeling Language (UML) untuk memvisualisasikan proses transaksi penjualan yang terjadi. Diagram yang digunakan adalah diagram use case, diagram aktivitas, dan diagram kelas. Bahasa pemrograman yang digunakan adalah PHP dengan Codeigniter, dan MySQL sebagai databasenya. Hasil dari analisis dan perancangan sistem ini mencakup formulir pengguna, formulir pendaftaran pelanggan, formulir pemrosesan transaksi, dan formulir pemrosesan laporan.
\end{abstract}

Kata kunci: Point of Sales, Bahasa Pemodelan Terpadu, PHP, Codeigniter, Web

\section{PENDAHULUAN}

Perkembangan teknologi dan sistem informasi perkembangan yang relevan dengan era Industrial. Kebutuhan informasi menjadi kebutuhan yang primer bagi kehidupan masyarakat saat ini. Pencapaian kebutuhan akan informasi ini tak lepas dari perkembangan teknologi internet yang memungkinkan berbagai jenis informasi diperoleh tanpa mengenal batas ruang dan waktu.

Website atau situs web merupakan teknologi internet yang dapat dijadikan fasilitas utama yang berfungsi sebagai sumber informasi bagi khalayak dalam bentuk penyimpanan data dan informasi berupa Uniform Resourch Locator (URL). Perusahaan baik berskala besar maupun kecil berangsur bermigrasi ke arah optimalisasi pemanfaatan internet baik untuk aktivitas, penjualan, promosi, keuangan, pelaporan, dan lain sebagainya . Hal ini dilakukan tentunya bukan tanpa alasan melainkan para pelaku usaha ini menginginkan hal yang optimal pula dalam mengatur keberlangsungan usaha dan optimalisasi kualitas pelayanan terhadap customer. (dikutip dari suwardi, 2011).

CV Putri Cahaya Cemerlang (Gudang Kopi Oncak) merupakan gudang kopi yang beralamat di Ruko Pasar Alam No. 78, Perumahan Vida Bantar Gebang, Kota Bekasi. Adanya kendala di sistem Gudang Kopi diantaranya Sistem pemasarannya masih secara manual, Pencatatan data pelanggan, Pencatatan data karyawan, Pencatatan stok barang dan Pencatatan laporan transaksi masih ditulis dalam buku besar dan Jumlah pembayaran masih menggunakan kertas bon.

Untuk itu CV Putri Cahaya Cemerlang (Gudang Kopi Oncak) ini sangat membutuhkan sebuah sistem yang terkomputerisasi dalam menghitung jumlah karyawan, jumlah pelanggan, jumlah stok barang dan jumlah transaksi, agar tidak mengurangi waktu yang cukup lama untuk mengetahui jumlahnya secara detail. Sistem informasi ini dapat dipergunakan sebagai pedoman untuk berkaitan dengan pencatatan jasa kopi terhadap pelanggan dan adanya sistem di Gudang Kopi Oncak dapat membantu untuk meringankan kinerja pencatatan data karyawan, pencatatan data pelanggan, jumlah stok barang, jumlah transaksi yang dapat dilihat berdasarkan tanggal berapa hingga tanggal berapa dan bisa mempermudah karyawan dalam membuat pencatatan laporan yang selama ini masih belum berjalan dengan baik. 
Point Of Sales (POS) adalah sebuah sistem untuk melakukan pengelolaan transaksi yang di dalamnya termasuk juga penggunaan mesin kasir. Dalam lingkup POS, sebuah mesin kasir tidak berdiri sendiri, namun sudah termasuk di dalamnya software penunjang dan piranti lain. Sistem POS selain untuk transaksi jual beli juga dapat langsung terintegrasi dengan perhitungan rekapitulasi transaksi harian, mingguan, atau tahunan, pengelola produk kopi dan stok kopi.

Mesin POS lebih mengacu kepada penggunaan teknologi untuk melakukan efisiensi transaksi, dalam hal ini adalah kecepatan, ketelitian dan kelengkapan pelaporan transaksi jual beli.

\section{METODE PENELITIAN}

\section{Tahapan-tahapan Metode Waterfall}

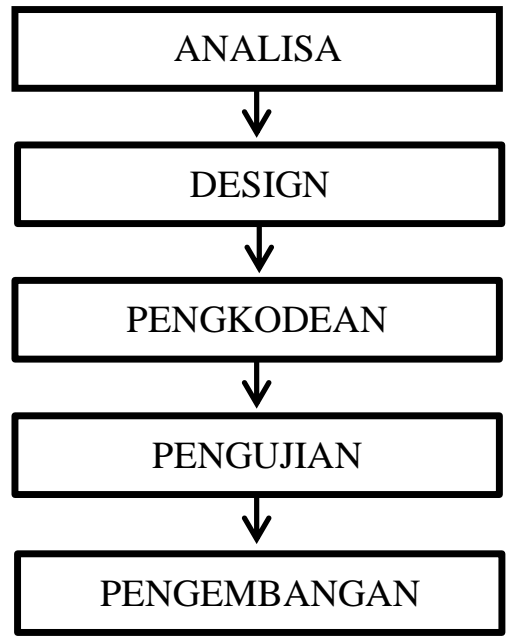

Gambar 1. Tahapan-tahapan Metode Waterfall

Dapat diuraikan masing-masing tahap dalam penelitian sebagai berikut:

1) Analisa

Tahap ini adalah tahap dimana keterkaitan dan sinkronisasi transaksi pada perangkat lunak tertentu dengan data yang ada sangat dibutuhkan untuk perjalanan prosesnya

2) Design

Tahap ini adalah tahap dimana perangkat keras dan keseluruhan arsitektur komputer terkait satu sama lain untuk dirancang menjadi sebuah alur sistem.

3) Pengkodean

Tahap ini adalah tahap dimana sistem dibuat dan dirancang dalam sebuah program kecil atau biasa disebut unit yang dapat diuji secara fungsionalnya.

4) Pengujian

Unit yang terimplementasi nantinya harus melalui tahap pengujian ini untuk mengetahui bentuk kesalahan atau kegagalan sistem yang dibuat.

5) Pengembangan

Perangkat lunak yang terbentuk akan diproses untuk dijalankan serta akan dilakukan upaya pemeliharaan yang nantinya dijadikan sebagai titik tolak aksi selanjutnya dalam proses evaluasi.

\section{HASIL DAN PEMBAHASAN}

\subsection{Sejarah CV Putri Cahaya Cemerlang (Gudang Kopi Oncak)}

Gudang kopi oncak yang beralamat di Jl. Ruko Pasar Alam No.78, Perumahan Vida, Bantar Gebang Bekasi. Kopi Oncak ini mampu bersaing dengan kopi lainnya. Dengan pelayanan berkualitas bagi kepuasan pelanggan, CV Putri Cahaya Cemerlang (Gudang Kopi Oncak) buka cabang pada beberapa kota dan cabang pusat berada di kota Palembang. 
Arti kata Oncak di dalam Bahasa Palembang memiliki arti yaitu Jagoan, Berdiri atau Terdepan. CV Putri Cahaya Cemerlang (Kopi Oncak) berdiri pada Tahun 2018, dan mulai launching (meluncurkan) pada Tahun 2019. CV Putri Cahaya Cemerlang (Gudang Kopi Oncak) cabang Bantar Gebang mulai launching (meluncurkan) pada Tanggal 01 Bulan Maret Tahun 2020.

Gudang Kopi Oncak cabang Bantar Gebang menyediakan beberapa ukuran kemasan produk yaitu: 50Gram, 100Gram, 250Gram dan $1 \frac{1}{2}$ Kilogram.

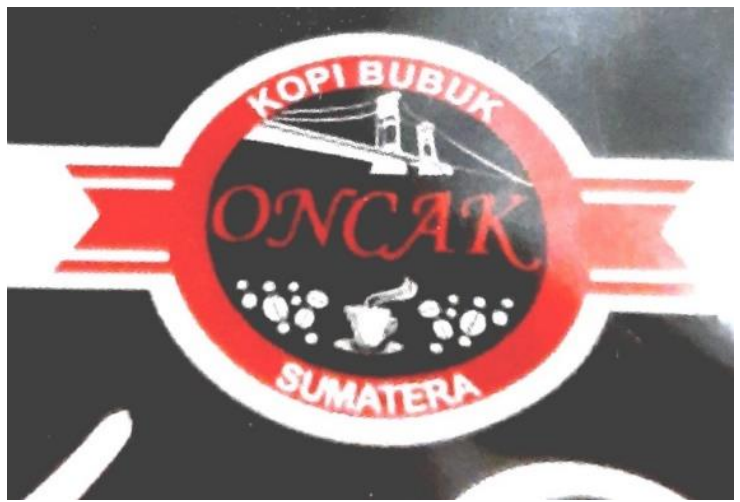

Gambar 2. Logo Kopi Oncak

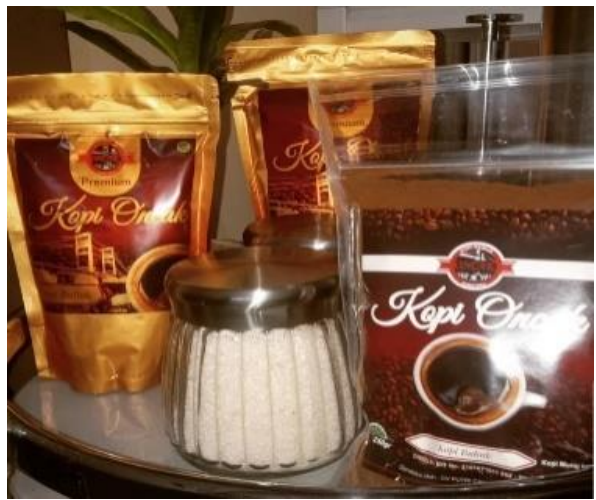

Gambar 3. Kopi Oncak

\subsection{Analisis Sistem yang Berjalan}

Adapun proses sistem yang berjalan pada CV Putri Cahaya Cemerlang (Gudang Kopi Oncak) Cabang Bantar Gebang sebagai berikut: CV Putri Cahaya Cemerlang (Gudang Kopi Oncak) Cabang Bantar Gebang memiliki 7 Karyawan. Adapun sistem pemasarannya yaitu hanya ke Warung-warung saja. Gudang kopi oncak ini belum memiliki Sosial Media apa pun, sistem pembayaran masih menggunakan kertas Bon dan Karyawan membuat laporan penjualan yang masih manual yaitu ditulis dalam buku besar, lalu mengirimkan laporan kepada pimpinan melalui email.

\subsection{Use Case Diagram}

1) Use Case Diagram Admin

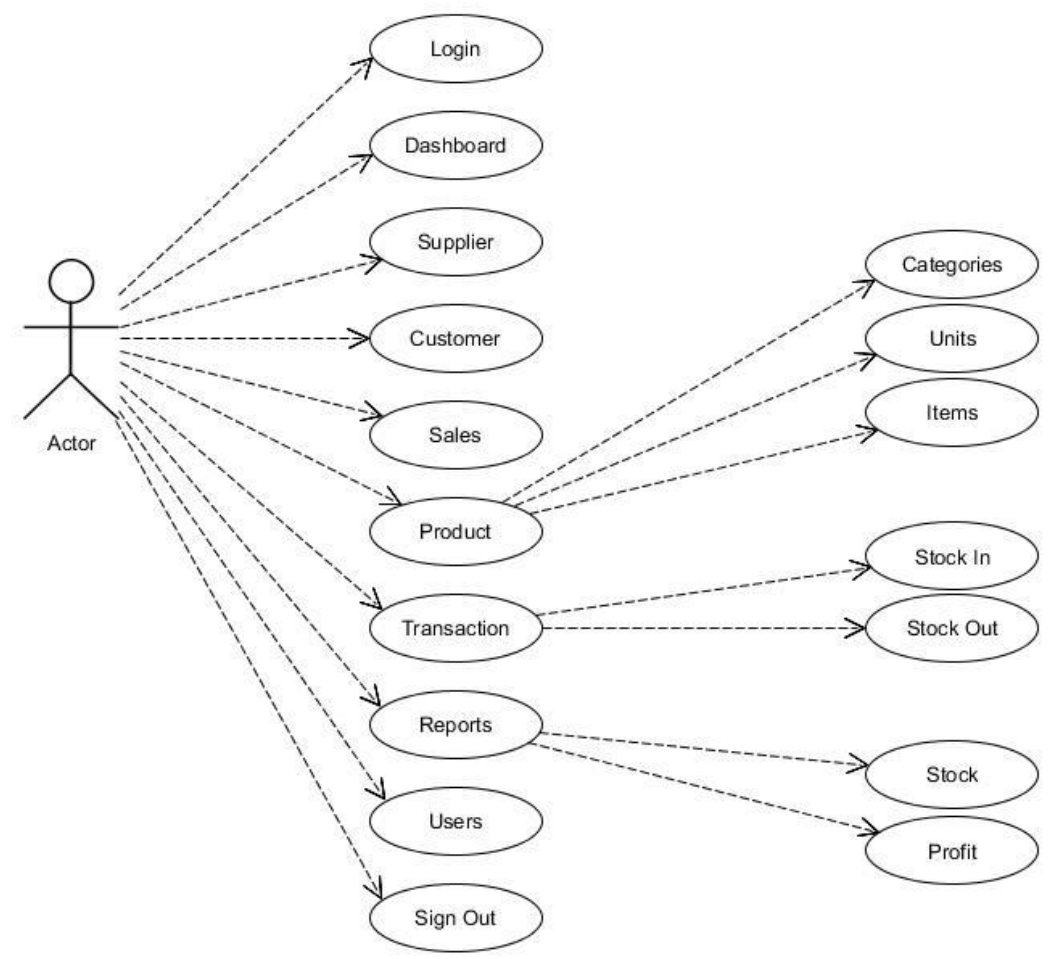

Gambar 4. Use Case Diagram Admin 


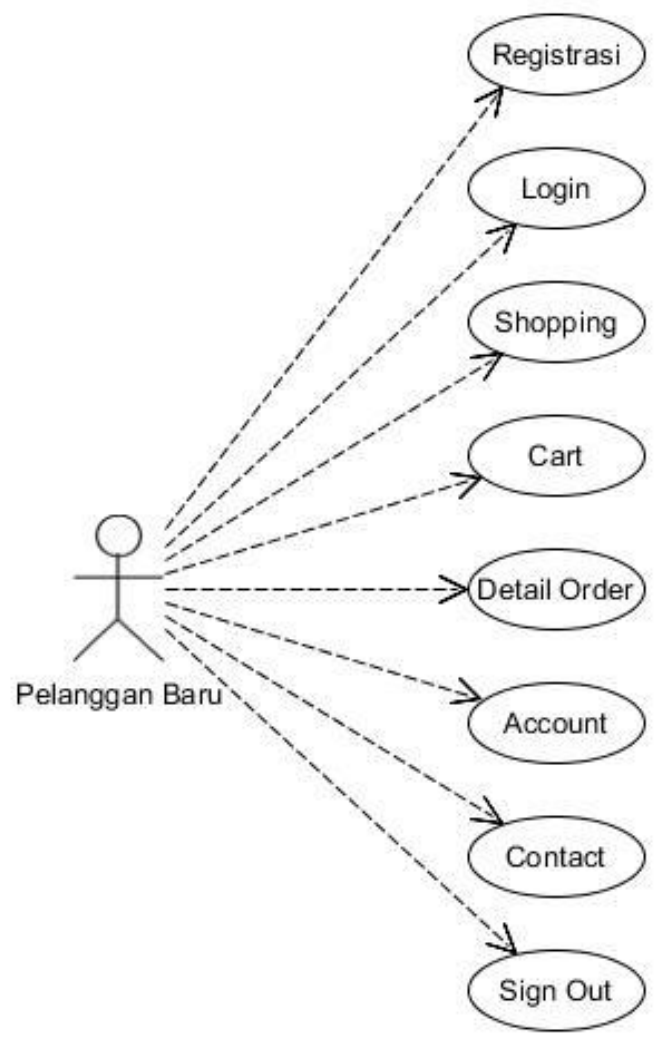

Gambar 5. Use Case Diagram Pelanggan

3) Class Diagram

Perancangan struktur data dalam proses analisis perancangan sistem pada kasus ini dapat ter visualisasi dalam diagram class, sebagai berikut:
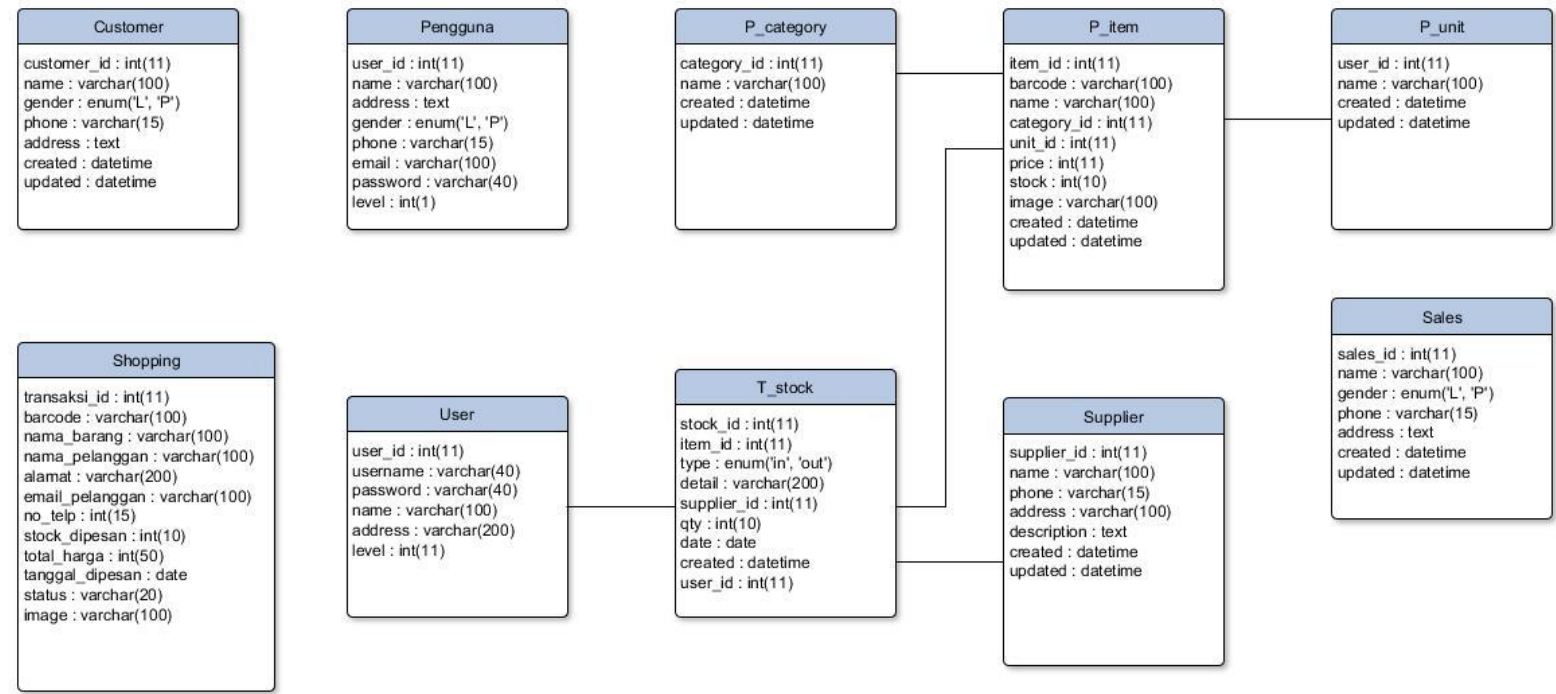

Gambar 6. Class Diagram

\subsection{Implementasi Sistem}

Proses implementasi sistem pada kasus ini adalah proses untuk menyelesaikan perancangan sistem yang ada dan menyesuaikan dengan dokumen rancangan sistem yang telah valid sebelumnya, proses pengujian sistem dan pemakaian sistem itu sendiri. Tujuan dari proses implementasi sistem adalah menerapkan sistem tersebut dan mengevaluasi kelebihan dan kekurangan sistem agar dapat dilakukan perbaikan. 


\subsection{Implementasi Tools}

1) Spesifikasi Perangkat Keras (Hardware)

Tabel 1. Spesifikasi Perangkat Keras

\begin{tabular}{|c|l|l|l|}
\hline No. & Perangkat Keras (Hardware) & Jumlah & \multicolumn{1}{|c|}{ Keterangan } \\
\hline 1. & Notebook & 1 Unit & $\begin{array}{l}\text { Spesifikasi minimal } \\
\text { a. Storage : 232 GB } \\
\end{array}$ \\
& & & $\begin{array}{l}\text { b. Memory : 4096MB RAM } \\
\text { c. Processor : Intel i3-6006U CPU }\end{array}$ \\
\hline
\end{tabular}

2) Spesifikasi Perangkat Lunak (Software)

Tabel 2. Spesifikasi Perangkat Lunak

\begin{tabular}{|c|l|l|}
\hline No. & \multicolumn{1}{|c|}{ Perangkat Lunak (Software) } & \multicolumn{1}{|c|}{ Keterangan } \\
\hline 1. & Windows 10 64 bit & Sistem Operasi \\
\hline 2. & Xampp Versi 7.4.4 & Web Server \\
\hline 3. & PHP & Bahasa Pemrograman \\
\hline 4. & MySQL & Database \\
\hline 5. & Sublime Text 3 & Penulisan Kode Program \\
\hline 6. & Mozilla Firefox & Web Browser \\
\hline 7. & CodeIgniter & Web Aplikasi \\
\hline 8. & Yed Graph Editor & Perancangan Diagram UML \\
\hline
\end{tabular}

\subsection{Implementasi Antarmuka Pemakai (User Interface)}

Implementasi Antarmuka Pemakai (User Interface/UI) merupakan implementasi keberdayagunaan sistem dengan optimalisasi antarmuka (Interface) dimana hal tersebut digunakan juga untuk mengkonfirmasi sejauh mana sistem menerima informasi dari pengguna (user) dan memberikan informasi kepada pengguna (user) dalam operasionalnya.

Dalam implementasinya sistem penjualan miliki Gudang Oncak ini dibuat dalam dua jenis, yaitu:

1) Graphical User Interface (GUI): menampilkan dalam bentuk komponen multimedia (seperti gambar, suara, video) yang dapat berinteraksi dengan user.

2) Text-Based: menampilkan perintah tertentu pada user untuk berinteraksi dengan sistem.

\subsection{Implementasi Website Admin}

1) Login Admin

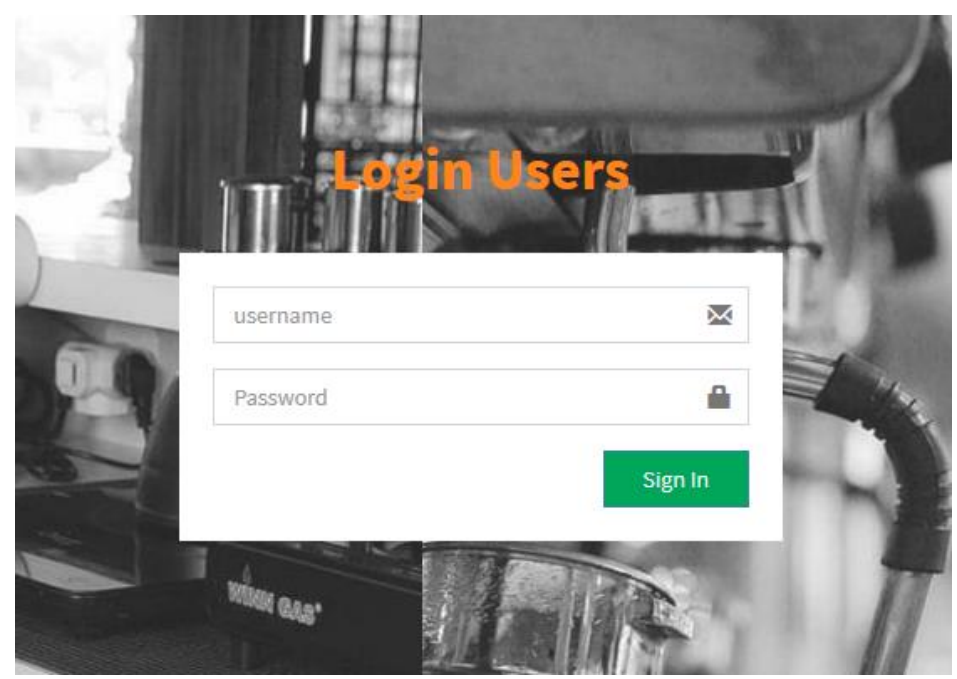

Gambar 7. Tampilan Login Admin 
2) Implementasi Dashboard Halaman Admin

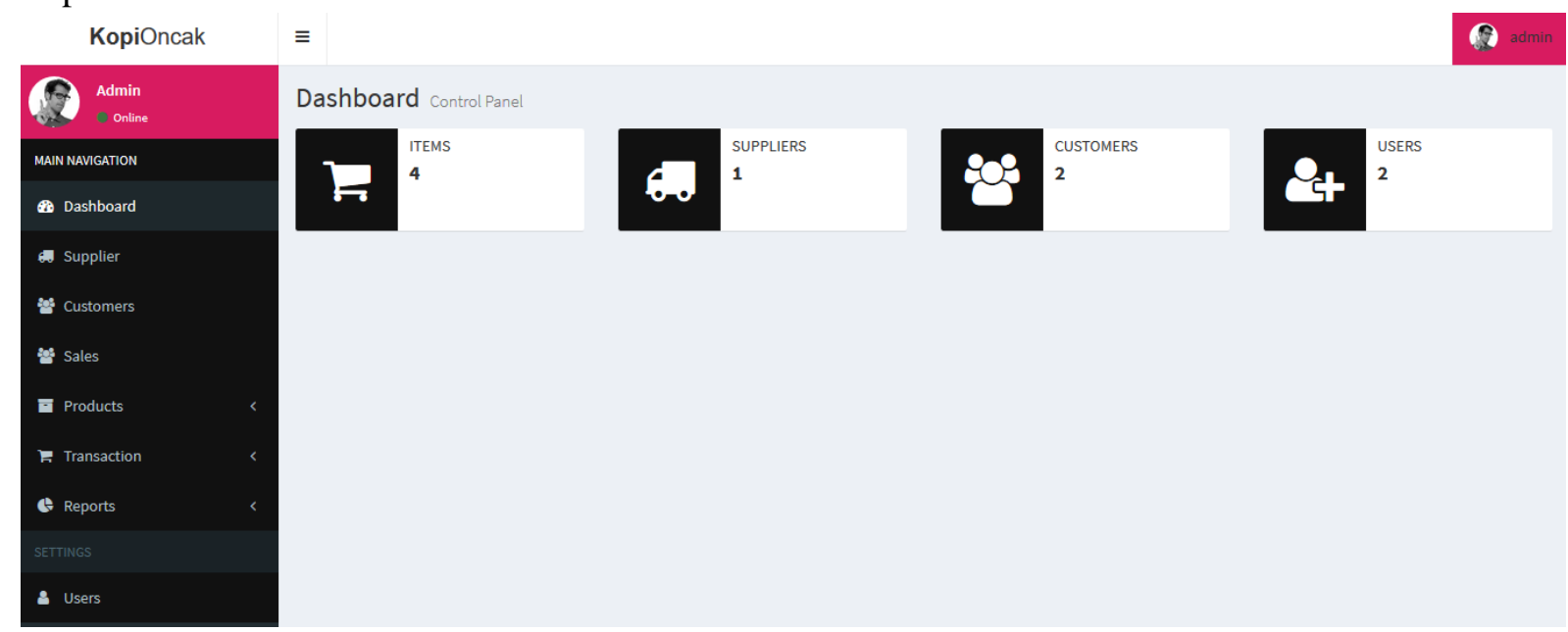

Gambar 8. Tampilan Dashboard Halaman Admin

3) Implementasi Sales Halaman Admin

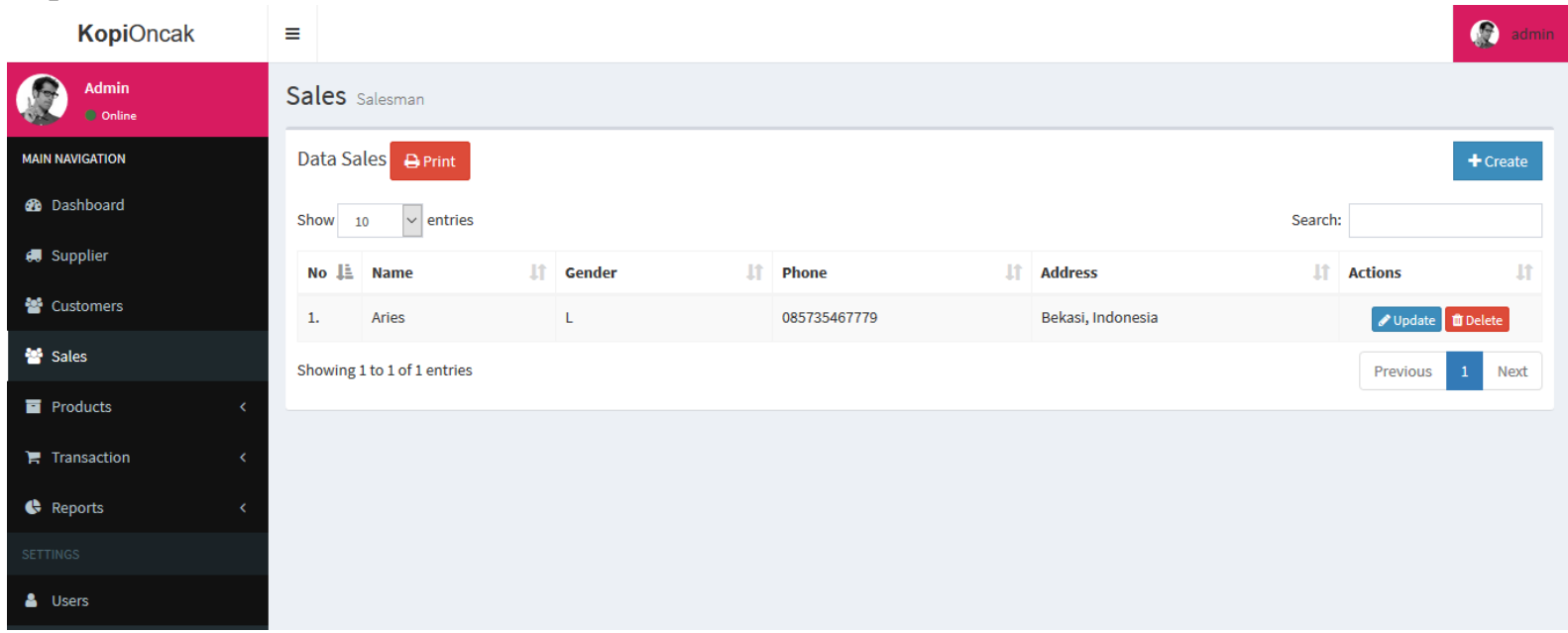

\section{Gambar 9. Tampilan Sales Halaman Admin}

4) Implementasi Item
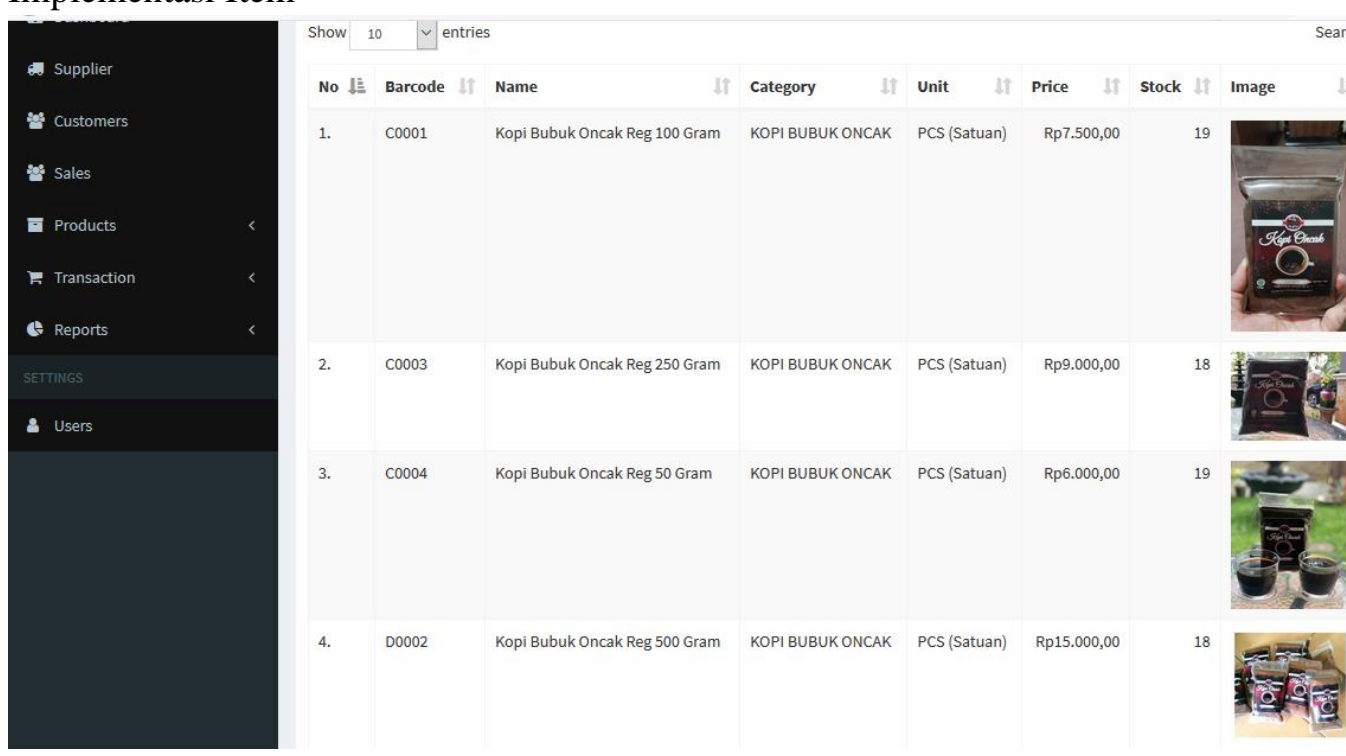

Gambar 10. Tampilan Item Halaman Admin 
5) Implementasi Profit

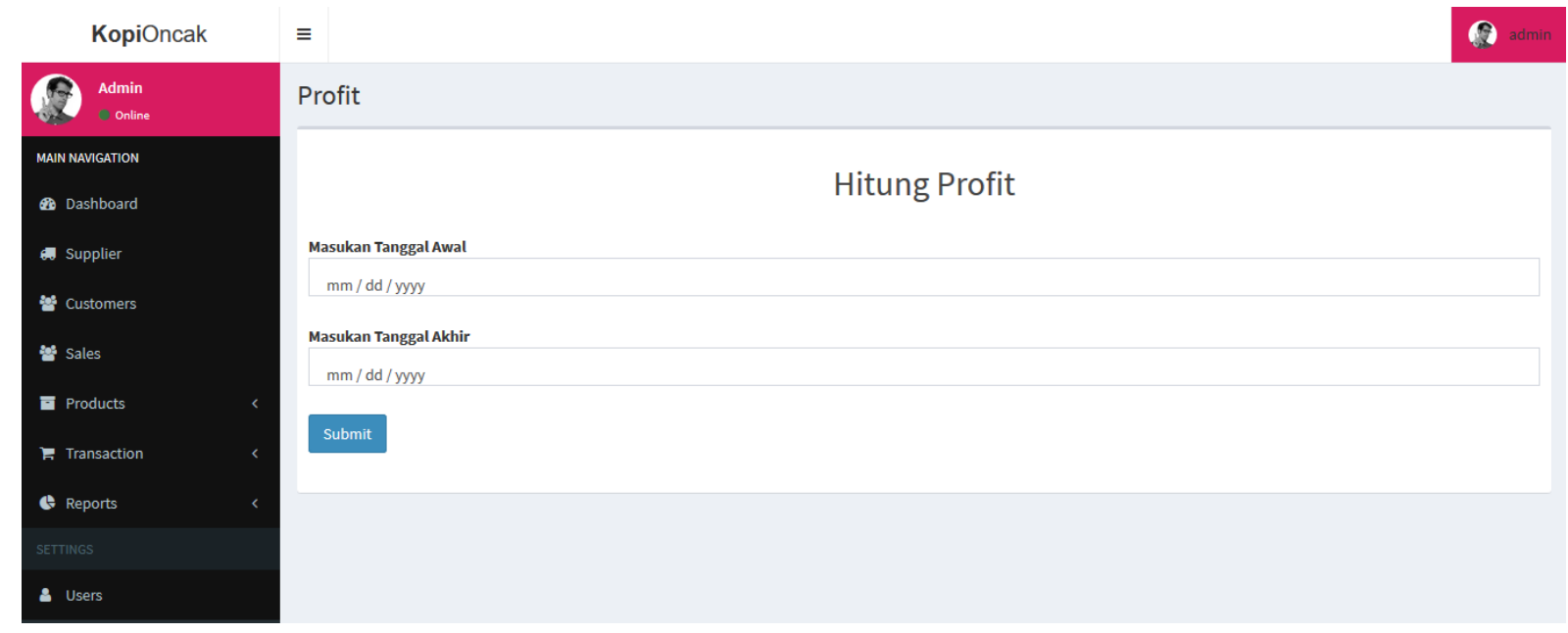

\section{Gambar 11. Tampilan Profit Halaman Admin}

\subsection{Implementasi Website Pelanggan}

1) Registrasi Akun Pelanggan

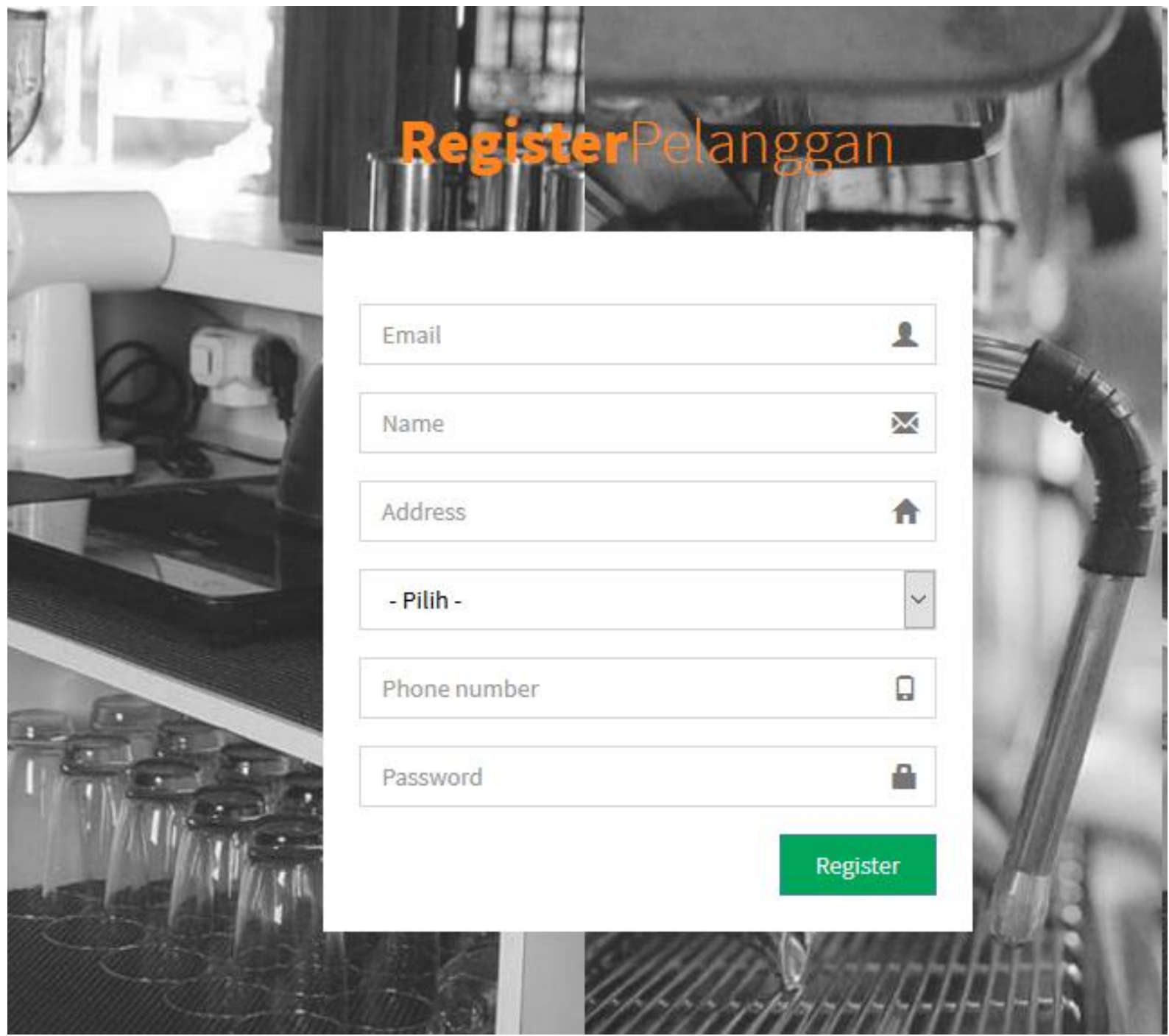

Gambar 12. Tampilan Registrasi Akun Pelanggan 
2)

Login Pelanggan

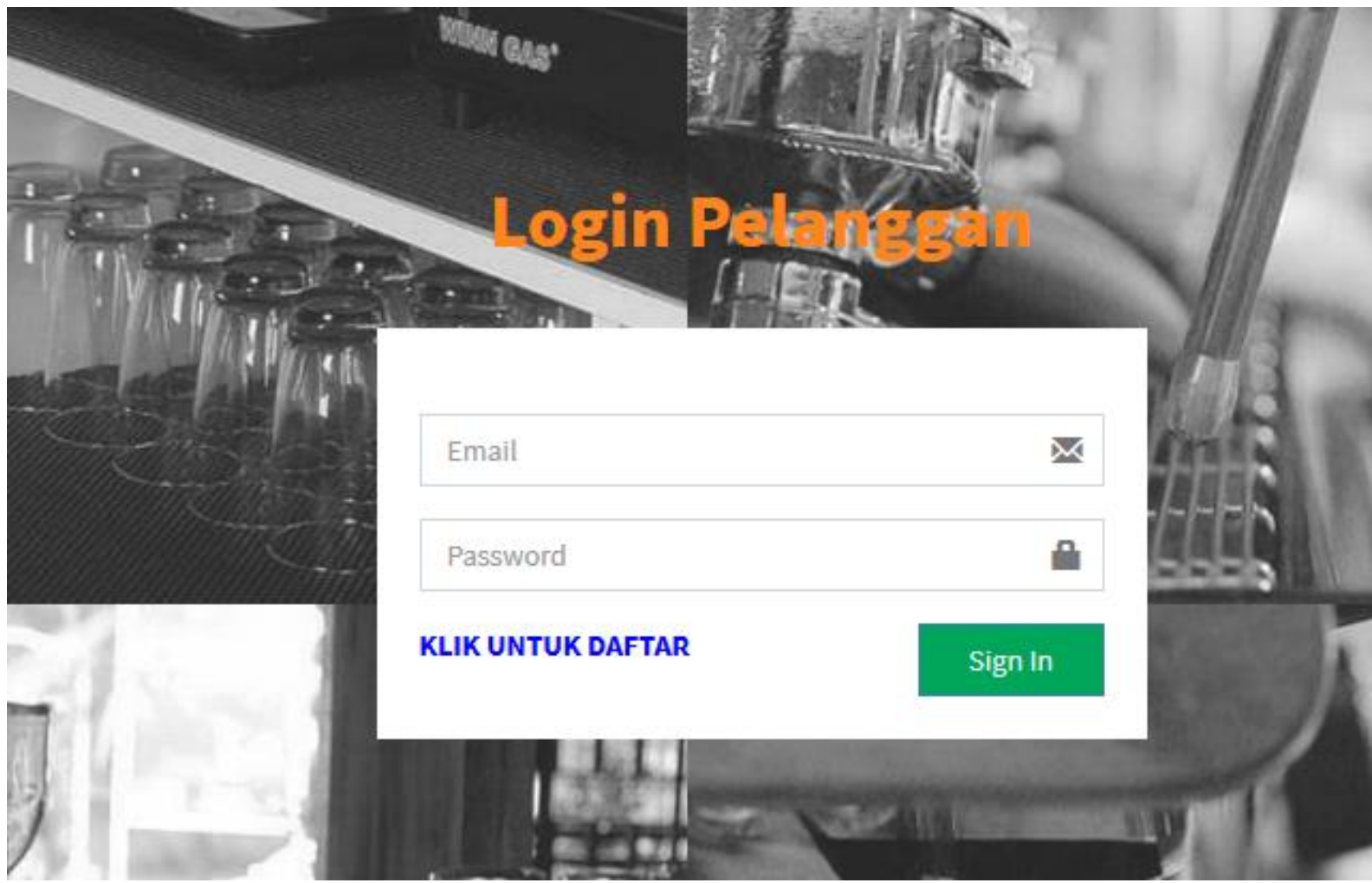

Gambar 13. Tampilan Login Pelanggan

3) Implementasi Shopping Halaman Pelanggan
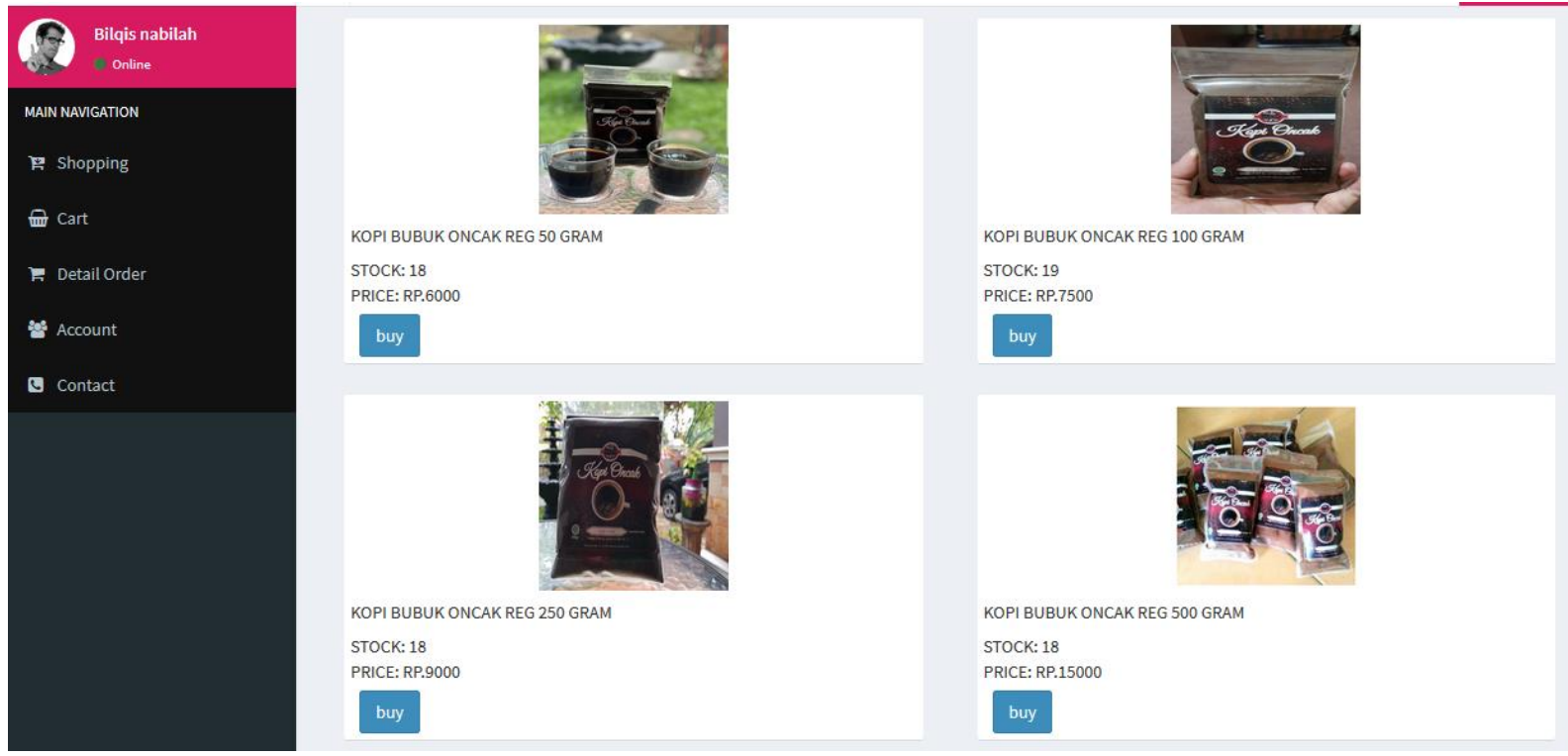

Gambar 14. Tampilan Shopping Halaman Pelanggan

\section{KESIMPULAN}

Simpulan yang terdapat dari hasil implementasi "Sistem Informasi Point Of Sales (POS) Berbasis Web di Gudang Kopi Oncak “ ini adalah bahwa sistem POS ini adalah suatu sistem terkomputerisasi yang diharapkan akan dapat membantu karyawan dalam mengelola data-data dan laporan yang tidak akan memakan waktu lama dan juga dapat membantu pelanggan dalam melakukan pemesanan secara online. Namun sistem ini masih membutuhkan pengembangan lebih lanjut yang nantinya membutuhkan struk pembelian, laporan berkala dan tentunya perbaikan tampilan site ini ke arah site yang lebih user friendly. 


\section{DAFTAR PUSTAKA}

Pengertian Point Of Sale. (2018). Retrieved Maret 31, 2020, from Mokapos.com: https://blog.mokapos.com/2015/09/08/definisi-dan-fungsi-dari-point-of-sale-pos

(2020, Februari 28). Retrieved Maret 29, 2020, from SumberPengertian.ID: https://www.sumberpengertian.id/pengertian-website

Landasan Teori. (n.d.). Retrieved April 01, 2020, from bsi.ac.id: https://repository.bsi.ac.id/index.php/unduh/item/199/file_10-bab-2-landasan-teori.pdf

Supono. (2013, Januari 22). Cara Install Codeigniter. Retrieved Maret 25, 2020, from Persinggahan Supono: https://supono.wordpress.com/2013/01/22/cara-install-codeigniter/

Tinjauan Pustaka. (n.d.). Retrieved April 02, 2020, from polsri.ac.id: http://eprints.polsri.ac.id/1068/3/Bab\%202.pdf

Yayankrist. (n.d.). Konsep Dasar Sistem. Retrieved Maret 27, 2020, from unikom.ac.id: https://elib.unikom.ac.id/files/disk1/709/jbptunikompp-gdl-yayankrist-35449-6-unikom y-i.pdf 